\title{
Energy Saving Design of Exterior Envelope of Prefabricated Buildings in Alpine Area
}

\author{
Tianli Chen ${ }^{1^{*}}$, Yingjun Wang ${ }^{2}$, Yaoqiang Wang ${ }^{3}$ \\ ${ }^{1}$ Architectural and Civil Engineering Institute, Zhengzhou Shengda University, Zhengzhou, Henan, China \\ ${ }^{2}$ Department of Civil Engineering, Xucahng University, Xuchang, Henan, China \\ ${ }^{3}$ Zhumadian Huayu Electric Power Design Co.Ltd, Zhumadian, Henan, China
}

\begin{abstract}
:
In this paper, the exterior envelope of prefabricated buildings in alpine areas is studied. This paper compares the wind resistance of the fabricated structure composed of two different connection modes, connectors with different thickness, lightweight ceramsite concrete peripheral wall panel and wood composite peripheral wall panel. The test results show that the wind resistance of the fabricated structure composed of wood wallboard mainly depends on the thickness of wallboard, connection mode and connector thickness. Whether sand packing is filled or not has no effect on the improvement of wind resistance of this prefabricated enclosure structure. For meeting the wind resistance of the fabricated enclosure used in the support room, it is recommended to use thick wooden wallboard and connect up and down. The wind resistance of the fabricated enclosure composed of wood wallboard mainly depends on the strength of the wood wallboard itself. The use of wood wallboards with higher thickness can improve the wind resistance of this fabricated structure.
\end{abstract}

Keywords: Wooden Wallboard, Wooden Structure, Alpine Area, Prefabricated Building.

\section{INTRODUCTION}

According to the key points and basic objectives of the 12th Five Year Plan for housing security, efforts should be made to solve the housing difficulties of low-income families, promote the transformation of various shantytowns and the comprehensive improvement of old residential areas, and establish and improve housing security policies and technical support systems [1-2]. Indemnificatory housing construction has ushered in a large-scale construction period, and will be the focus of the work of local government departments at all levels for a long time. At present, it is urgent to improve the standard system of indemnificatory housing [3]. The standardization of indemnificatory housing construction is conducive to improving the 
Article History: Received: 28 October 2021 Revised: 05 December 2021 Accepted: 10 January 2022 Publication: 28 February 2022

construction level and realizing the overall goal of "housing security" [4-5].

Indemnificatory housing refers to the housing with limited standards, prices or rents provided by the government for low - and middle-income families with housing difficulties. It is generally a small-scale house type and large-scale construction, which is very suitable for the implementation of standardized design, industrialized application of component production and integration of construction and decoration. Housing industrialization is the manufacturing of housing by large-scale industrialized production mode, so as to improve production efficiency and overall quality, and effectively reduce building energy consumption, which is very consistent with the construction requirements of indemnificatory housing [6]. It plays a great role in promoting the government and the whole society to achieve the goal of "housing".

This paper is one of the sub topics of the national science and technology support plan project "research and demonstration of key technologies for the industrialized design and construction of indemnificatory housing" in the 12th Five Year Plan [7].

\section{EXPERIMENTAL STUDY ON WIND RESISTANCE BEARING CAPACITY OF PREFABRICATED RETAINING STRUCTURE}

\section{Test design basis}

This paper mainly studies the wind resistance of prefabricated enclosure structure composed of lightweight concrete wallboard and composite wallboard with different thickness under different connection modes. Considering the economy and operability of the test, the wind load is simulated by uniformly distributed load in this test. The working condition of the retaining structure under wind load is realized by horizontally arranging the retaining structure and applying vertical uniform load. Study its wind resistance according to its maximum bearing capacity and deformation, so as to provide reference for the next envelope design.

Test basis [8-9]:

Technical specification for fabricated concrete structures

Code for design of concrete structures

Code for load of building structures

Code for Acceptance of Construction Quality of Concrete Structure Engineering

Standard for Test Methods of Basic Performance of Sand Installation in Buildings

In the design process of isolated structure, on the premise of ensuring the use function, the structural form of large column spacing is adopted. On the one hand, the increase of bearing spacing can improve the height width ratio limit of the structure. On the other hand, the increase of bearing spacing will also increase the diameter of isolation bearing, which can increase the deformation limit of isolation layer. In addition, because the isolation bearing in the model is selected according to the maximum axial force of the column, the bearing at the corner column is too large. If the bearing is selected according to the corresponding surface pressure at the 
Article History: Received: 28 October 2021 Revised: 05 December 2021 Accepted: 10 January 2022 Publication: 28 February 2022

bottom of the column, the limit value of height width ratio can be further improved.

2.Experimental material properties and specimen fabrication

The wall panel material selected in the test is fabricated prefabricated wall panel. In this test, two kinds of prefabricated wall panels widely used in the market are selected, namely lightweight ceramsite concrete wall panel and composite thermal insulation outer wall panel [10]. Lightweight ceramsite concrete wallboard (hereinafter referred to as Jianhua wallboard) is provided by Jiangsu Jianhua new wall material Co., Ltd., and composite thermal insulation exterior wall board (hereinafter referred to as Huali wallboard) is provided by Beijing Huali united high tech company. The dimensions of wallboard are shown in Table 1.

TABLE I. Dimension table of wallboard

\begin{tabular}{|c|c|}
\hline TYPE OF WALLBOARD & WALL PANEL SIZE $($ MM) \\
\hline \multirow{2}{*}{ JIANHUA WALLBOARD } & $2600 \times 600 \times 120$ \\
\cline { 2 - 2 } & $2600 \times 500 \times 150$ \\
\hline \multirow{3}{*}{ GORGEOUS WALLBOARD } & $3470 \times 600 \times 150$ \\
\cline { 2 - 2 } & $3000 \times 600 \times 120$ \\
\cline { 2 - 2 } & $3000 \times 600 \times 90$ \\
\hline
\end{tabular}

The mortar is provided by two wall panel manufacturers, namely Jianhua wall panel dry mixed mortar and gorgeous wall panel binder. During the wind bearing capacity test of fabricated enclosure structure specimens, according to the standard for test methods of basic performance of building mortar, each group of cube specimens shall be tested for cube compressive strength at the same time. The compressive strength test data of two kinds of mortar and binder are shown in Table 2 below.

TABLE II. Mortar compressive strength test data

\begin{tabular}{|c|c|c|c|c|c|}
\hline $\begin{array}{c}\text { GORGEOUS } \\
\text { BINDER }\end{array}$ & $\begin{array}{c}\text { TEST } \\
\text { PIECE }\end{array}$ & $\begin{array}{c}\text { TEST } \\
\text { PIECE 2 }\end{array}$ & $\begin{array}{c}\text { TEST } \\
\text { PIECE 3 }\end{array}$ & $\begin{array}{c}\text { AVERAGE } \\
\text { VALUE }\end{array}$ & $\begin{array}{c}\text { DISCRETE } \\
\text { COEFFICIENT }\end{array}$ \\
\hline $\begin{array}{c}\text { 7-DAY } \\
\text { COMPRESSIVE } \\
\text { STRENGTH (MPA) }\end{array}$ & 12.3 & 11.3 & 9.6 & 11.1 & 0.123 \\
\hline JIANHUA MORTAR & Test piece & Test piece 2 & Test piece 3 & Average value & Discrete coefficient \\
\hline $\begin{array}{c}\text { 7-DAY } \\
\text { COMPRESSIVE } \\
\text { STRENGTH (MPA) }\end{array}$ & 4.8 & 4.2 & 4.3 & 4.4 & 0.073 \\
\hline
\end{tabular}


Article History: Received: 28 October 2021 Revised: 05 December 2021 Accepted: 10 January 2022 Publication: 28 February 2022

Note: the 7-day strength is the cube compressive test strength of the specimen at the same time

The experimental device is designed as follows: the specimen is placed horizontally, and the stacking load is $250 \mathrm{~mm} \times 140 \mathrm{~mm} \times 10 \mathrm{~mm}$, and the weight of each piece is $20 \mathrm{~kg}$.

According to the test conditions and reusability, steel beams are used at the upper and lower ends of the test piece, which can fix the connector and mortar formwork.

The specific arrangement of the two connection modes of the wallboard is as follows: the first connection mode is upper connection and lower cushion, that is, one side of the wallboard is connected with the steel beam through the steel U-clamp connector and bolts. The other side shall be bonded with the special dry masonry mortar provided by the manufacturer. The second connection mode is up-down connection, that is, one side of the wallboard is connected with the steel beam through the steel U-clamp connector, and the other side is connected with the steel beam through the L-shaped connector.

Before formal loading, check the reliability of the test device and whether all observation instruments work normally. As it is a vertical load, the self weight of the wall panel shall be determined as the first level load before loading. The self weight of the wall shall be calculated respectively according to the surface density of the test specimen measured by the test side of the cooperative unit Beijing Institute of building engineering in this paper.

Before loading, snap the weight placement reference line on the loading surface of the test piece with an ink line in advance, and determine the loading sequence in different areas to ensure that it is as close to the uniformly distributed load as possible. When loading, it shall be placed according to the datum line. Each time it is loaded, read the indication of the dial indicator, and then continue to add according to the pre-designed position. During loading, observe the deformation, cracking and failure of the specimen, and load it step by step until it is damaged. Determine the loading system according to the estimated load.

The isolation structure system consists of superstructure, isolation layer and substructure. In order to achieve the expected isolation effect, the isolation layer must have four basic characteristics: (1) it has large vertical bearing capacity and safely supports the superstructure; (2) With variable horizontal stiffness, the stiffness before yield can meet the requirements of wind load and micro vibration. When a strong earthquake occurs, its small post yield stiffness makes the isolation system into a flexible system, effectively separates the ground vibration and reduces the seismic response of the superstructure; (3) With horizontal elastic restoring force, the isolation system has the function of reset in earthquake; (4) It has sufficient damping and large energy dissipation capacity.

3.Test process and result analysis

According to the connection mode, the 8 specimens of Jianhua enclosure structure are divided into two connection types, among which KF-JH2, KF-JH3, KF-JH4, KF-JH5 and KF- 
Article History: Received: 28 October 2021 Revised: 05 December 2021 Accepted: 10 January 2022 Publication: 28 February 2022

JH6 are connected up and down, KF-JH1 and KF-JH7, KF-JH8 are connected up and down.

Based on the mortar cracking load, wallboard cracking load and envelope failure load of each fabricated envelope composed of Jianhua wallboard, in order to make the test results easier to analyze, the cracking load, failure load and failure form of eight Jianhua wallboard envelope specimens loaded in the test are summarized in Table 3. The secondary stiffness of the isolation layer is the sum of the secondary stiffness of the lead rubber bearing and the horizontal stiffness of the natural rubber bearing. After the lead core yields, it does not provide horizontal stiffness, which is equivalent to that only the natural rubber bearing provides horizontal stiffness. The horizontal stiffness of rubber bearings with the same diameter is basically the same, so the secondary stiffness is basically the same

TABLE III. Summary of cracking and failure of Jianhua wallboard specimens

\begin{tabular}{|c|c|c|c|c|}
\hline SPECIMEN NAME & $\begin{array}{c}\text { MORTAR } \\
\text { CRACKING } \\
\text { LOAD (KG) }\end{array}$ & $\begin{array}{c}\text { CRACKING LOAD OF } \\
\text { WALLBOARD (KG) }\end{array}$ & $\begin{array}{c}\text { FAILURE } \\
\text { LOAD (KG) }\end{array}$ & FAILURE FORM \\
\hline $\begin{array}{c}\text { KF-JH1(DOUBLE } \\
\text { PLATE) }\end{array}$ & 1080 & 1520 & 2830 & $*$ \\
\hline $\begin{array}{c}\text { KF-JH2(DOUBLE } \\
\text { PLATE) }\end{array}$ & 1240 & 1240 & 2000 & Connector failure \\
\hline $\begin{array}{c}\text { KF-JH3(DOUBLE } \\
\text { PLATE) }\end{array}$ & - & 1160 & 2000 & Connector failure \\
\hline $\begin{array}{c}\text { KF-JH4(DOUBLE } \\
\text { PLATE) }\end{array}$ & - & 720 & 1600 & Connector failure \\
\hline $\begin{array}{c}\text { KF-JH5(DOUBLE } \\
\text { PLATE) }\end{array}$ & - & 720 & 2712 & Wall panel failure \\
\hline $\begin{array}{c}\text { KF-JH6(SINGLE } \\
\text { BOARD) }\end{array}$ & - & 640 & 1540 & Wall panel failure \\
\hline $\begin{array}{c}\text { KF-JH7(SINGLE } \\
\text { BOARD) }\end{array}$ & 720 & 720 & 800 & Mortar failure \\
\hline $\begin{array}{c}\text { KF-JH8(SINGLE } \\
\text { BOARD) }\end{array}$ & 600 & 620 & 680 & Mortar failure \\
\hline
\end{tabular}

According to the connection mode, the nine specimens of gorgeous wall panel enclosure structure are divided into two connection types, among which the specimens KF-HI1,KF-HL(1), KF-HL2, KF-HL3, KF-HL6, KF-HL7 and KF-HL8 are one, and the specimens KF-HL4 and KF-HL8 are connected with each other.

The mortar cracking load, wallboard cracking load and envelope failure load of each fabricated envelope composed of gorgeous wallboard are obtained through the experiment. In order to make the test results easier to analyze, the cracking load, failure load and failure form 
January-February 2022 Page No.124-131

Article History: Received: 28 October 2021 Revised: 05 December 2021 Accepted: 10 January 2022 Publication: 28

February 2022

of the specimen of gorgeous wallboard envelope loaded in the test are summarized in Table 4.

TABLE IV. Summary of cracking and failure of gorgeous wallboard specimens

\begin{tabular}{|c|c|c|c|c|}
\hline SPECIMEN NAME & $\begin{array}{c}\text { MORTAR } \\
\text { CRACKING } \\
\text { LOAD (KG) }\end{array}$ & $\begin{array}{c}\text { CRACKING } \\
\text { LOAD OF } \\
\text { WALLBOARD } \\
\text { (KG) }\end{array}$ & $\begin{array}{c}\text { FAILURE } \\
\text { LOAD } \\
\text { (KG) }\end{array}$ & FAILURE FORM \\
\hline $\begin{array}{c}\text { KF-HL1 (DOUBLE } \\
\text { BOARD) }\end{array}$ & - & 480 & 480 & Wall panel fracture \\
\hline $\begin{array}{c}\text { KF-HL(1) (DOUBLE } \\
\text { BOARD) }\end{array}$ & - & 480 & 480 & Wall panel fracture \\
\hline $\begin{array}{c}\text { KF-HL2 (DOUBLE } \\
\text { BOARD) }\end{array}$ & - & 180 & 520 & Wall panel fracture \\
\hline $\begin{array}{c}\text { KF-HL3 (DOUBLE } \\
\text { BOARD) }\end{array}$ & - & 480 & 1000 & Wall panel fracture \\
\hline $\begin{array}{c}\text { KF-HL4 (SINGLE } \\
\text { BOARD) }\end{array}$ & 400 & 480 & 560 & Mortar fracture \\
\hline $\begin{array}{c}\text { KF-HL5 (SINGLE } \\
\text { BOARD) }\end{array}$ & 220 & 300 & 300 & Wall panel fracture \\
\hline $\begin{array}{c}\text { KF-HL6 (SINGLE } \\
\text { BOARD) }\end{array}$ & - & 480 & 1200 & Wall panel fracture \\
\hline $\begin{array}{c}\text { KF-HL7 (DOUBLE } \\
\text { BOARD) }\end{array}$ & - & 480 & 520 & Wall panel fracture \\
\hline $\begin{array}{c}\text { KF-HLS (DOUBLE } \\
\text { BOARD) }\end{array}$ & - & 540 & Wall panel fracture \\
\hline
\end{tabular}

\section{ABAQUS FINITE ELEMENT CALCULATION RESULTS}

The essence of finite element analysis is to transform the infinite degree of freedom problem into a finite degree of freedom problem, and the continuum model into a discrete model composed of finite elements. ABAQUS element library provides a wealth of element types, which can simulate almost any geometric finite element model in practical engineering.

Finite element material parameters:

(1) Wallboard

1) Modulus of elasticity. According to the national architectural standard design reference drawing of steel structure inlaid ASA board energy-saving building structure provided by Jianhua wallboard manufacturer, Jianhua wallboard belongs to light ceramsite concrete wallboard, and its elastic modulus is about 1600mpa.

2) Density. According to the two wall panel tests conducted by Beijing Institute of Architectural Engineering in the early stage, the area density of two types of wall panels with 
Article History: Received: 28 October 2021 Revised: 05 December 2021 Accepted: 10 January 2022 Publication: 28 February 2022

different thickness was measured respectively.

\section{(2) Connector}

The connectors of the test pieces studied in this paper are made of Q235 steel. Refer to Chapter III for specific style and size. The elastic modulus is $20 \mathrm{GPa}$, Poisson's ratio is 0.3 and the density is $7.85 \mathrm{~g} / \mathrm{cm}^{3}$.

The initial slope of the curve of the specimen with mortar filling is greater than that of the specimen without mortar filling, which indicates that the filled mortar is a fabricated enclosure structure, and the stiffness increases; However, in the later stage of loading, the slope of the curve tends to be consistent, indicating that after the specimen cracks in the later stage, the mortar stops working, and the mortar has little effect on the final wind bearing capacity of the specimen. This conclusion can be obtained by comparing the test results with the numerical simulation results. The reason why the mid span displacement in the test load displacement curve is too small is that the dial gauge is limited in the test, which is removed in advance when the specimen is not completely damaged. In addition, because the deformation caused by wallboard cracking is not considered in the numerical simulation, the inflection point of the numerical simulation curve is not obvious compared with the test curve.

Due to the different connection modes, the failure loads of the two specimens are quite different. It is analyzed that the reason is that the tensile strength of the mortar is limited. After the wallboard is deformed, the mortar at the mortar connection will crack quickly. The final shear failure affects the failure load of this kind of prefabricated retaining structure, which directly affects the wind resistance and bearing capacity of the prefabricated retaining structure. In addition, due to the limitation of numerical simulation software, the relative displacement between wallboard and mortar can not be fully simulated, so there is a certain error between the numerical simulation limit displacement of specimen KF-JH8 and the test value.

Through comparison, it is found that the change of connector thickness has no effect on the overall stiffness of the envelope. However, the use of 4mm thick Q235 connector can greatly increase the failure load of the fabricated envelope relative to $3 \sim$ thickness. Comparing the test load displacement curve with the numerical simulation load displacement curve, it can be found that the numerical simulation results of the initial section are the same as the test results, and there are differences in the latter half, because the numerical simulation can not well simulate the crack development of the wallboard after the cracks appear in the wallboard.

\section{CONCLUSION}

As a new type of structure, prefabricated building envelope is more and more widely used with the promotion of national housing industrialization policy. As a new construction technology, it has many advantages, such as light weight, short construction period, increasing use area, saving energy and improving labor efficiency. Through reasonable selection of 
Article History: Received: 28 October 2021 Revised: 05 December 2021 Accepted: 10 January 2022 Publication: 28 February 2022

wallboard type, wallboard thickness, connector thickness and connection mode. So that it can not only meet the envelope function and use function of the outer envelope of the support room, but also have good wind resistance bearing capacity, which is of great practical significance for its application in the support room project. Firstly, according to the wind load theory and building structure load code, the standard value of wind load of prefabricated enclosure structure at different heights is determined. Then, the wind bearing capacity of the fabricated envelope composed of Jianhua wallboard and gorgeous wallboard is studied. The effects of wall panel type, wall panel thickness, connector thickness and connection mode on the wind resistance of prefabricated enclosure structure are analyzed, and compared with the wind load value required by the application support room of this structure, the structural form meeting the wind load requirements is determined. Then the numerical simulation analysis and theoretical verification are carried out, and the design direction of envelope structure is given.

\section{REFERENCES}

1. Jiang Chuanliang, Xian Qiaoling. Nonlinear Finite Element Analysis of Reinforced Concrete Structures. Science and Technology and Engineering, 2005, 5 (017): 1323-1324

2. Niu Bin. Analysis of Flexural Behavior of Externally Prestressed Concrete Beams. Acta Civil Engineering, 1999 (04): 37-44

3. Cai Shaohuai. the Latest Development of Concrete Filled Steel Tubular Structure Technology in China. Acta Civil Engineering, 1999, 32 (004): 16-26

4. Zhu Y, Qiu J, Du H, et al. Simultaneous optimal design of structural topology, actuator locations and control parameters for a plate structure. Computational Mechanics, 2002, 29(2):89-97.

5. Guo Zhenhai, Wang Chuanzhi. Study on Strength and Failure Criterion of Concrete Under Multiaxial Stress. Acta Civil Engineering, 1991, 024 (003): 1-14

6. Nie Jianguo, Yu Zhiwu. Research and Application of Steel-concrete Composite Beams in China. Acta Civil Engineering, 1999, 32 (2): 3-8

7. Zhou Junsheng, Lou Zhuanghong. Present Situation and Development Trend of Long Span Prestressed Concrete Continuous Rigid Frame Bridge. Acta Highway Sinica, 2000, 13 (1): 9-13

8. Lu Xilin, Lu Weidong. Experimental Study on Seismic Behavior of Concrete Filled Steel Tubular Columns Under Cyclic Loading. Acta Architectural Structures, 2000 (2):12-19

9. Yuan Yingshu, Jia Fuping, Cai Yue. Structural Performance Degradation Model of Corroded Reinforced Concrete Beams. Acta Civil Engineering, 2001, 34 (003): 47-52

10. Ye Lieping, Lu Xinzheng, Ma Qianli. Seismic Nonlinear Analysis Model, Method and Example of Concrete Structure. Engineering Mechanics, 2006, 23 (0z2): 131-140 